ARTIGO DE REVISÃO

\title{
Psicoterapia breve pais-bebê: revisando a literatura
}

\author{
Short-term parent-infant psychotherapy: a review of the literature
}

\author{
Luiz Carlos Prado'; Aline Grill Gomes" ; Giana Bitencourt Frizzo' ; Cristiane A dos Santos" ; \\ Daniela Delias de Souza Schwenberger" ; Rita Sobreira Lopes "II; Cesar Augusto Piccinini ${ }^{\text {IV }}$ \\ 'Psiquiatra e Psicoterapeuta, Membro, Instituto da Família de Porto Alegre, Porto Alegre, RS. \\ "Psicóloga. Doutora, Psicologia, Universidade Federal do Rio Grande do Sul (UFRGS), Porto Alegre, \\ RS. \\ IIIDoutora. Docente, Programa de Pós-Graduação em Psicologia, UFRGS. \\ IV Psicólogo. Docente, Programa de Pós-Graduação em Psicologia, UFRGS. Doutor. Pesquisador, \\ Conselho Nacional de Desenvolvimento Científico e Tecnológico (CNPq).
}

Este estudo foi realizado no Instituto de Psicologia, Universidade Federal do Rio Grande do Sul (UFRGS), Porto Alegre, RS.

\section{Endereço para correspondência}

\begin{abstract}
RESUMO
Este artigo apresenta uma revisão da literatura a respeito da psicoterapia breve pais-bebê. Inicialmente são apresentados aspectos históricos, desde o surgimento da psicoterapia breve, passando pelas formulações teóricas que enfatizaram a importância das relações iniciais pais-bebê até a constituição do campo da psicoterapia breve pais-bebê propriamente dita. Constata-se que várias abordagens compõem o panorama atual das psicoterapias pais-bebê, as quais apresentam uma ampla diversidade de referenciais teóricos e técnicos. Foram também revisados, em particular, estudos empíricos sobre a utilização dessa abordagem no contexto da depressão materna. Por fim, apresentam-se os procedimentos utilizados pelos autores deste artigo em uma pesquisa em andamento envolvendo o atendimento psicoterápico breve pais-bebê em famílias com mães deprimidas. Essa abordagem tem se mostrado efetiva na promoção de um melhor relacionamento mãe-pai-bebê na presença sintomas depressivos da mãe.
\end{abstract}

Descritores: Psicoterapia pais-bebê, pesquisa em psicoterapia, depressão materna.

\footnotetext{
ABSTRACT

This article presents a review of the literature on short-term parent-infant psychotherapy. Initially, some historical aspects are presented since the emergence of short-term psychotherapy, including the theoretical formulations that highlighted the importance of early parent-infant relationships and helped to implement the field of short-term parent-infant psychotherapy. There are several approaches to parent-infant psychotherapy, representing a broad diversity of theoretical and technical frameworks. Empirical studies were also reviewed, especially those using parent-infant psychotherapy in the context of maternal depression. Finally, the authors' experience with short-term parent-infant psychotherapy involving families with depressive mothers was presented. This approach has shown to be effective in the promotion of better mother-father-infant relationship in the presence of maternal depressive symptoms.
} 
Keywords: Parent-infant psychotherapy, psychotherapy research, maternal depression.

\section{NTRODUÇÃO}

A psicoterapia breve pais-bebê tem sido uma das abordagens que vem sendo recentemente mais utilizada no tratamento dos distúrbios nas relações iniciais pais-bebê. O presente estudo buscou caracterizar esse tipo de intervenção, desde o surgimento da psicoterapia breve até a forma como tem sido utilizada atualmente. A pesquisa bibliográfica incluiu os últimos 20 anos de publicação em artigos, a partir dos descritores psychotherapy, brief psychotherapy, parent-infant psychotherapy, mother-infant psychotherapy e postpartum depression utilizados nas bases de dados PsychINFO e MEDLINE. Os mesmos termos em português foram utilizados em busca na Biblioteca Virtual em Saúde (BVS). Foram também revisados inúmeros livros nacionais e internacionais, especialmente de autores clássicos que trabalharam com psicoterapia.

\section{CARACTERI ZAÇÃO E ASPECTOS HISTÓRI COS}

Essas especificidades, em termos de demanda, indicação e/ou objetivos terapêuticos, produziram uma série de modificações na técnica analítica clássica, as quais fazem da terapia breve uma forma distinta de tratamento3. Dessa forma, a psicoterapia breve não é definida apenas pelo tempo de duração. O essencial é que, a partir de uma compreensão diagnóstica do paciente, seja estabelecido um foco de trabalho e objetivos terapêuticos, limitados e dirigidos aos sintomas e problemática atual. Há, portanto, um planejamento de meta e uma duração do tratamento, sendo estes previamente fixados por paciente e terapeuta ${ }^{4}$.

A literatura aponta que alguns autores foram fundamentais na viabilização e sistematização da psicoterapia breve, embora não sejam considerados teóricos dessa abordagem. Dentre eles, Freud costuma ser considerado um precursor, na medida em que seus primeiros tratamentos eram de curta duração e, geralmente, focalizavam os sintomas1,3. Além disso, a revisão da literatura realizada por Hartke5 destaca o papel de Ferenczi e Rank, que, na década de 1920, introduziram modificações técnicas importantes no procedimento psicanalítico tradicional a fim de abreviar o tratamento. Ainda segundo Hartke5, Ferenczi propôs, em particular, a chamada "técnica ativa", cujo principal objetivo era incitar a emergência de conflitos muito reprimidos e, portanto, pouco reconhecíveis, através de ordens ou proibições dadas pelo analista, as quais muitas vezes contrariavam o princípio da associação livre. Rank, por sua vez, introduziu algumas modificações teóricas, com a ênfase colocada no trauma do nascimento como o nódulo central da neurose. Ele acreditava na possibilidade de um tratamento psicanalítico breve para superar, em poucos meses, a ansiedade primordial advinda desse trauma. Uma contribuição importante de Rank para a psicoterapia breve foi o estabelecimento prévio de uma data para o término da análise ${ }^{5}$.

O início da psicoterapia breve como uma técnica propriamente dita se deu através do trabalho de Alexander \& French ${ }^{4}$ na década de 1940 . Além de caracterizar os princípios técnicos dessa abordagem - como flexibilidade do terapeuta, estabelecimento de objetivos e planejamento do tratamento -, eles cunharam o conceito de experiência emocional corretiva. Esse conceito enfatiza o momento atual e a relação terapêutica, em vez da rememoração de experiências do passado.

Posteriormente, nas décadas de 1960 e 1970, outros autores, como Malan, Balint e Sifneos, deram seguimento a essa abordagem psicoterápica, realizando novos avanços teóricos e técnicos, especialmente através de trabalhos empíricos realizados em Londres e nos EUA ${ }^{5}$. A partir daí, a psicoterapia breve ganhou formulações mais delimitadas e foi se constituindo em um amplo e diversificado campo de estudo e atuação.

O desenvolvimento da psicoterapia breve, em suas diferentes abordagens, trouxe para o campo das psicoterapias não apenas uma modificação de natureza técnica, mas também uma mudança de caráter teórico. Ao lado de um modelo que se centrava no intrapsíquico e pulsional para explicar a constituição psíquica e as psicopatologias, criou-se uma nova perspectiva de compreensão desses 
processos, a qual foi denominada por Greenberg \& Mitchell ${ }^{6}$ de modelo estrutural-relacional. Essa abordagem defende que a constituição psíquica teria como base as primeiras relações do bebê com o ambiente, e as psicopatologias derivariam de dificuldades nessas relações.

\section{MPORTÂNCI A DAS RELAÇÕES I NICI AIS}

As primeiras relações do bebê com seu ambiente já se iniciam durante a gestação, através das expectativas parentais sobre o bebê e das interações estabelecidas com ele ${ }^{7-10}$. Depois do nascimento, os pais seguem depositando no bebê suas fantasias e expectativas, as quais ele responderá de acordo com suas características, formando-se um padrão de relação pais-bebê. Dentro desse padrão, Brazelton \& Cramer $^{11}$ consideraram tanto a interação objetiva pais-bebê quanto o significado subjetivo dessa relação. Esse significado subjetivo, construído com base nas interações vividas no decorrer do desenvolvimento do indivíduo, especialmente com as figuras parentais, constitui as interações imaginária pais-bebê. Estas englobam as fantasias dos pais a respeito de si mesmos, de seus parentes mais próximos, bem como seus ideais e medos.

Assim, diversos autores defendem que essas primeiras relações são fundamentais para a estruturação da personalidade, transcendendo a concepção kleiniana de que o bebê se comportaria predominantemente em resposta às demandas do seu mundo interno ${ }^{6}$. Dentre estes autores, destacam-se Sullivan, Winnicott, Bion, Fairbairn, Mahler, Spitz e os interacionistas Bowlby, Brazelton e Stern ${ }^{12}$.

Em uma revisão teórica a respeito das diferentes abordagens das relações objetais, Greenberg \& Mitchel ${ }^{6}$ ressaltaram que, apesar de algumas divergências, todos os autores acima citados enfatizaram que o desenvolvimento psíquico ocorre a partir das experiências emocionais vividas nos vínculos humanos. Segundo esses autores, Sullivan defendeu enfaticamente esse ponto de vista ao romper com a teoria freudiana, sugerindo que cada um dos princípios da teoria pulsional poderia ser melhor compreendido em termos de processos interpessoais e sociais. Para ele, o objeto de estudo da psiquiatria seria as interações. Winnicott ${ }^{13}$ também enfatizou a importância do ambiente, o qual teria o papel de auxiliar a criança a passar de uma posição de dependência absoluta para uma relativa independência. Para tanto, é necessário que a mãe (ou cuidador) seja "suficientemente boa", ou seja, possa atender às necessidades do bebê, sendo continente às suas angústias, mas, ao mesmo tempo, viabilizar o grau "ótimo" de frustração que estimule o seu desenvolvimento.

Seguindo esta linhagem teórica, Bion ${ }^{14}$ desenvolveu o conceito de função de reverie materna, que prevê a capacidade da mãe de receber os elementos alfa - angústia, agressividade - nela colocados pelo bebê por identificação projetiva. Ela precisaria processar esses elementos, tornando-os digeríveis para o bebê (elementos beta), constituindo nele a capacidade de pensar.

A busca de relação com o outro foi apontada por Fairbairn ${ }^{6}$ como a principal motivação para os comportamentos e experiências infantis, tirando o foco da descarga pulsional como base para as relações interpessoais. Ele também postulou que os primeiros meses de vida da criança centram-se em uma experiência de fusão com a mãe, à qual deve seguir-se uma progressiva separação. Duas décadas depois, Mahler ${ }^{15}$ retomou essa visão, identificando diversas fases no processo de separaçãoindividuação da criança em relação à mãe, com base na observação do comportamento de bebês. Ela afirmava que o modo como a dupla passa por essas etapas - desde a diferenciação até a consolidação da individuação - leva a um desfecho mais próximo da saúde ou da patologia. Spitz ${ }^{16}$ por sua vez, salientou a importância da relação mãe-filho desenvolvendo o conceito de depressão anaclítica do bebê, que é o declínio físico e psíquico em resposta à privação da mãe.

Os interacionistas introduziram a dimensão do comportamento social precoce, enfatizando a comunicação bidirecional contínua entre os pais e o bebê ${ }^{12}$. Dentre esses autores, destaca-se aqui o trabalho de Bowlby ${ }^{17}$, que desenvolveu a teoria do apego inicialmente a partir de observações de crianças sem lar. Para Bowlby ${ }^{18}$, o bebê apresenta comportamentos de apegos dirigidos ao cuidador, que consiste em alcançar e manter proximidade com ele(a), considerado mais apto para lidar com o mundo. A disponibilidade dessa figura de apego fornece ao bebê um sentimento de segurança forte, o que encoraja a pessoa a valorizar e continuar a relação. Além dessas contribuições teóricas, Cramer \& Palacio-Espasa ${ }^{12}$ destacaram que os interacionistas, especialmente Bowlby, ao fornecerem 
um método para a observação sistemática da interação, fizeram também uma importante contribuição metodológica para a psicoterapia pais-bebê.

\section{AS PSI COTERAPIAS BREVES PAIS-BEBÊ}

As contribuições de todos os autores apresentados anteriormente, além das de outros interessados na qualidade dos aspectos relacionais e interacionais para o desenvolvimento emocional do indivíduo, como Fraiberg ${ }^{19}$ e Lebovici ${ }^{20}$, contribuíram para o surgimento das psicoterapias conjuntas mãe-bebê ou pais-bebê. Essas surgiram a partir da necessidade de contemplar a notável mobilização psíquica dos pais e a velocidade das modificações subjetivas, interativas e sintomáticas que se operam particularmente entre a mãe, o pai e o bebê no puerpério ${ }^{12}$. Nesse período, observa-se uma forma particular de funcionamento psíquico, na qual ocorre a redistribuição dos investimentos parentais. Alguns autores indicam que esta mobilização psíquica pode iniciar já durante gravidez $^{13,21}$. A criança transforma-se em uma espécie de elo de ligação e depositária de investimentos que, até então, estavam ligados a objetos internos ou a aspectos do self dos pais. Sendo assim, a "entidade" examinada nas psicoterapias desse período refere-se a um sistema complexo, no qual convergem as seguintes tramas: os funcionamentos particulares do pai e da mãe; as contribuições do bebê; o relacionamento desses sistemas em uma psicoterapia; e as contribuições do terapeuta ${ }^{12}$.

A primeira abordagem psicoterápica pais-bebê foi proposta por Fraiberg nos anos 1970, a qual enfatizou a presença do bebê na psicoterapia pela sua força catalisadora ${ }^{12}$. Essa autora desenvolveu um trabalho a partir do Programa de Saúde Mental para o bebê, em Michigan, que objetivava atender famílias cujos bebês apresentavam sinais precoces de carência afetiva, sintomas graves ou lacunas do desenvolvimento ${ }^{19}$. O método de atendimento foi sendo desenvolvido paralelamente aos atendimentos e de acordo com as demandas específicas de cada caso. Por exemplo, diante da resistência de uma das famílias em comparecer ao centro de atendimento, foi proposta uma psicoterapia domiciliar. Utilizando sempre a psicanálise, a psicologia do desenvolvimento e o trabalho social, uma equipe de terapeutas propunha às famílias identificar, resgatar e vivenciar no tratamento os fantasmas do passado que estariam atuando no presente da criança. Desta forma, Fraiberg introduziu a dimensão transgeracional nas psicopatologias relacionais precoces.

Assim como Fraiberg, Lebovici ${ }^{20}$ também enfatizou os aspectos transgeracionais, além de estimular o estudo das interações do ponto de vista psicanalítico. Lebovici chamou a atenção dos psicanalistas para a importância do papel interacional na constituição psíquica precoce, e da dialética entre intrapsíquico e interpessoal, estimulando o estudo das interações ${ }^{12}$. Desenvolveu as chamadas consultas terapêuticas, as quais compreendem a observação da interação entre mãe, bebê e, quando necessário, outros membros da família, permitindo a evocação das fantasias dos pais projetadas sobre o bebê. $O$ terapeuta ajudaria os pais a compreender as motivações conscientes e inconscientes dos seus comportamentos relacionados ao bebê ${ }^{20}$.

A partir desses precursores, outras formas de intervenção pais-bebê foram propostas. Stern ${ }^{21}$ sistematizou alguns desses modelos de intervenção, tais como o uso de escalas para a avaliação do desenvolvimento do bebê, a observação da interação mãe-bebê e as psicoterapias pais-bebê. Para fins deste artigo, serão examinadas somente estas últimas: as psicoterapias pais-bebê propriamente ditas. De acordo com Stern, algumas dessas técnicas têm como objetivo modificar as representações dos pais em relação ao bebê, enquanto outras objetivam mudar os comportamentos interativos pais-bebê.

As representações dos pais referem-se aos aspectos do mundo subjetivo e imaginário. Estes incluem as fantasias dos pais, as esperanças, medos, sonhos, desejos, lembranças da própria infância, modelos de pais, expectativas para o futuro do bebê, além das experiências atuais sentidas na interação com o bebê ${ }^{21}$. Em relação às abordagens que visam alterar essas representações, uma das autoras citadas por Stern foi Dolto. Dolto ${ }^{22}$ propôs uma forma de psicoterapia que visava alterá-las através das representações do bebê, conforme imaginadas pela terapeuta. Sua abordagem caracterizava-se pela utilização de interpretações verbais diretas para o bebê, que seria capaz de compreendê-las quando bem colocadas. Ao ouvi-las, a mãe modificaria seu comportamento manifesto com o bebê e, portanto, o comportamento deste. Dolto defendia que o ser humano é, 
acima de tudo, um ser de linguagem. A palavra tem primazia, e mesmo quando uma comunicação é expressa através do corpo, esta tem um "sentido linguagem". Assim, a autora insiste na necessidade de falar ao bebê ou à criança, da palavra ser expressamente dita, e desta carregar uma verdade, por mais dura que seja. Para ela, só uma linguagem expressa e verdadeira abre a possibilidade para uma constituição psíquica sólida.

De acordo com Stern ${ }^{21}$, outros autores além de Dolto acreditaram que as representações dos pais deveriam ser modificadas pela psicoterapia pais-bebê, como Liebermann \& Pawl ${ }^{23}$, Cramer \& Palacio-Espasa ${ }^{12}$ e o próprio Stern. A psicoterapia bebê-pais, conforme proposta por Liebermann \& $\mathrm{Pawl}^{23}$, foi inspirada principalmente nos trabalhos da psicanalista Fraiberg. Nessa abordagem, 0 relacionamento bebê-pais é considerado o "paciente", e não somente os pais com seus mundos representacionais. Além disso, a qualidade da relação terapeuta-pais é vista como sendo o principal fator para o processo de mudança na relação pais-bebê, já que a experiência da relação com o terapeuta é entendida como uma possibilidade de apego corretivo.

Já a psicoterapia breve mãe-bebê, realizada por Cramer \& Palacio-Espasa ${ }^{12}$, busca efetuar a conexão temática entre os conflitos infantis da mãe (memórias e representações), seus temas conflituais atuais e a interação mãe-bebê atual. A interpretação desses conflitos é considerada a força maior de mudança nesta abordagem. De acordo com Pinto ${ }^{24}$, esse modelo de psicoterapia pode conduzir a mudanças positivas tanto no sintoma da criança como nas interações mãe-criança, ao considerar que as interações reais são um correlato visível das interações fantasmáticas. No tocante ao interesse pelas primeiras relações, Cramer \& Palacio-Espasa ${ }^{12}$ esclarecem a preocupação em decifrar a construção comum de sentido, procedente do encontro e da interpenetração do psiquismo dos pais e do filho, considerando as significações como resíduos de formas de relações objetais vividas ontem (a priori) e hoje (a posteriori).

Já a abordagem desenvolvida por Stern ${ }^{21}$, que também visa modificar as representações parentais, considera que os comportamentos interativos são o ponto de partida de uma busca do mundo representacional da mãe. Nessa abordagem, é frequente a utilização, durante as sessões, de gravações em vídeo da interação da mãe com o bebê. Estas oportunizam à mãe acessar suas representações e recordações, ligando-as ao interagido com o bebê.

Outras duas abordagens psicoterápicas revisadas por Stern ${ }^{21}$, a denominada orientação interacional e a familiar-sistêmica, não visam mudar as representações parentais, mas sim os comportamentos interativos entre pais e bebê. Essas abordagens partem do princípio de que existe um grau de reciprocidade entre o comportamento interativo dos pais e do bebê.

A orientação interacional desenvolvida por McDonough ${ }^{25}$ baseia-se na análise de videoteipes das sessões de psicoterapia, realizada junto com a família. Conforme revisão dessa técnica realizada por Schwengber et al. ${ }^{26}$, o foco dessa intervenção é melhorar o sentimento de competência dos pais em relação aos cuidados do bebê, salientando os aspectos positivos das interações familiares. Nessa abordagem, o terapeuta deve observar tanto a estrutura da interação, o que a díade ou a família faz, como o seu estilo. Além disso, embora não seja uma técnica interpretativa, considera o contexto do desenvolvimento dos pais enquanto filhos, no sentido de conhecer o equilíbrio da estrutura transgeracional, a existência de atritos parentais, papéis e relacionamentos disfuncionais, bem como a experiência da infância dos pais. Ainda segundo os autores, nessa abordagem a competência e a autoestima dos pais são reforçadas, sendo o principal objetivo o de realizar intervenções que modifiquem o comportamento problemático e, ao mesmo tempo, que promovam modelos saudáveis de comportamentos interacionais.

Para a abordagem familiar-sistêmica, tanto o indivíduo como seu processo de desenvolvimento são incluídos no estudo da família ${ }^{27}$. Em seus primórdios, o modelo sistêmico buscou se opor ao modelo psicodinâmico, centrando-se nas interações atuais do sistema familiar. Dessa forma, a compreensão dos sintomas, bem como o encaminhamento das soluções, desconsideravam a história da família. Atualmente, pode-se observar um movimento integrador que visa resgatar e readaptar algumas das conquistas mais importantes do modelo psicanalítico. Conforme Prado ${ }^{28}$, um exemplo disso é a importância do histórico na estruturação psíquica e na co-determinação da patologia dos indivíduos.

O modelo de intervenção breve e focal das terapias pais-bebê possui várias semelhanças com a terapia familiar ${ }^{29}$. Na concepção de Cramer \& Palacio-Espasa ${ }^{12}$, o foco estaria relacionado às 
dificuldades da relação mãe-bebê vinculadas a algum aspecto conflitivo de sua história. Na visão sistêmica de família, este foco também pode estar relacionado a algum aspecto da relação do casal ou da família mais ampla, articulado de alguma maneira com interações conflitivas passadas na família de origem do pai ou da mãe ${ }^{29}$.

Conforme o exposto acima, observa-se que várias abordagens compõem o panorama atual das psicoterapias pais-bebê, as quais apresentam uma ampla diversidade de referenciais teóricos e técnicos. Os autores do presente artigo, em sua maioria membros do Núcleo de Infância e Família (NUDIF)* vêm desenvolvendo pesquisas sobre a psicoterapia pais-bebê, tendo optado por utilizar principalmente a abordagem psicodinâmica de Cramer \& Palacio-Espasa ${ }^{12}$, juntamente com conceitos de Stern ${ }^{21}$ e da abordagem familiar-sistêmica ${ }^{29}$. Dessa forma, serão expostos a seguir, mais detalhadamente, aspectos dessas abordagens, bem como seus pontos de convergência.

\section{NTEGRANDO ABORDAGENS PSI COTERÁPI CAS PAIS-BEBÊ}

A psicoterapia breve mãe-bebê, conforme sistematizada por Cramer \& Palacio-Espasa ${ }^{12}$, está fundamentada no entendimento de que as psicopatologias do bebê devem ser compreendidas no contexto da relação pais-bebê, na medida em que decorrem de perturbações relacionais. De acordo com os autores, o tratamento psicoterápico conjunto de pais e bebê pode trazer uma melhora significativa nos sintomas no bebê, nos comportamentos interativos e nas representações acerca da parentalidade, sendo que este tratamento ocorre em três níveis: 1) determinação da natureza do sintoma e do confronto da mãe com o seu próprio conflito e a respeito do problema que é transferido ao bebê; 2) estabelecimento de uma conexão entre as falhas interacionais observadas durante a sessão e a correspondência mental do conflito na mãe; 3) estabelecimento de ligações entre o conflito presente da díade com os conflitos do passado da mãe. Para tanto, os autores consideraram fundamental o desenvolvimento e a manutenção da aliança terapêutica, da empatia e de uma transferência positiva.

Em consonância com a concepção de Cramer \& Palacio-Espasa a respeito da transferência, Stern ${ }^{21}$ postula que a transferência que se desenvolve no setting de psicoterapia pais-bebê envolve a elaboração de um desejo maior de apoio por uma figura materna. Sendo assim, ocorre uma busca desse papel na figura do terapeuta. Com isso, o terapeuta pode atuar de forma mais ativa e menos abstinente emocionalmente, centrando-se mais nos recursos, capacidades e forças do que na patologia e nos conflitos. Como resultado, de acordo com o autor, tende a ocorrer uma boa aliança terapêutica, através da qual o terapeuta se constitui em uma forma especial de matriz de apoio, capaz de sustentar a mãe a fim de que suas funções maternas sejam facilitadas.

Um outro aspecto referente à técnica da psicoterapia mãe-bebê proposta por Cramer \& PalacioEspasa $^{12}$ refere-se à atenção do terapeuta. Para os autores, esta deve ser igualmente dividida entre a observação das interações da díade mãe-bebê ou tríade pai-mãe-bebê e a escuta dos pais. 0 clínico irá privilegiar a observação da natureza das solicitações recíprocas e as reações a elas, através de modalidades interativas, tais como vocalizações, troca de olhares, toques e gestos. A partir dessas interações, o terapeuta poderá tecer interpretações para os pais a respeito de suas defesas intrapsíquicas. Isso ocorre quando há uma coincidência entre um enunciado de uma fantasia conflitiva e a atualização da defesa relacionada a esse conflito através de uma evitação, proibição, ruptura de contato, ou seja, um sintoma interativo observado, o que os autores chamaram de sequência interativa sintomática (SIS). Esta sequência é o equivalente interagido (e interpessoal) de um conflito intrapsíquico.

Ao analisar os fatores de mudança nas terapias breves mãe-bebê, Cramer \& Palacio-Espasa ${ }^{12}$ consideraram que, ao mudarem os investimentos e representações que têm do filho, os pais acabam por reduzir as projeções sobre a criança. De acordo com os autores, alterações no comportamento manifesto e nas representações dos pais podem ser observadas já no decorrer da segunda ou terceira sessão. Quando isso ocorre, observa-se, ao mesmo tempo, uma alteração nos investimentos dos pais sobre o filho e, consequentemente, na interação pais-bebê. Sendo assim, o objetivo da psicoterapia não é o de alterar todo o funcionamento psíquico dos pais, mas apenas um setor de investimento circunscrito à relação com o bebê, o que, para os autores, justifica a brevidade dessa técnica. 
Esta brevidade do tratamento é possível em decorrência de vários fatores: a velocidade das modificações subjetivas, interativas e sintomáticas; a mobilização psíquica da mãe, ou seja, sua capacidade de estabelecer vínculos, insight, mobilização dos afetos; e, finalmente, a neoformação psíquica característica do pós-parto, que abrange os primeiros anos de vida do bebê ${ }^{12}$. Corroborando esse ponto de vista, cabe salientar que as famílias com bebês parecem se adaptar bem ao modelo breve porque estão vivendo um intenso processo de desenvolvimento, necessitando que a sua relação seja ajustada continuamente às mudanças maturacionais que ocorrem com seus membros, sendo compatível com o ritmo evolutivo característico das trocas entre os pais e o bebê ${ }^{30}$.

De forma geral, o número de sessões da psicoterapia breve pais-bebê varia entre quatro e 12 , com uma média de seis sessões, uma vez por semana, com aproximadamente 60 minutos de duração ${ }^{12}$. O setting deve favorecer simultaneamente a capacidade de associação dos pais e a troca mais livre possível entre pais e filho, sendo que algumas vezes o terapeuta poderá brincar com a criança. Conforme os autores, a mãe, em geral, é quem apresenta mais angústia, depressão e preocupações obsessivas nesse período, o que explica porque é ela quem, na maioria das vezes, solicita a consulta. Contudo, quando o pai está presente, o tratamento deve se dirigir à tríade.

Nesse aspecto, quando inclui a tríade pai-mãe-bebê, a abordagem de Cramer \& Palacio-Espasa ${ }^{12}$ aproxima-se da abordagem familiar sistêmica ${ }^{29}$, a qual, conforme mencionado anteriormente, também embasa as intervenções psicoterápicas pais-bebê realizadas pelos pesquisadores do NUDIF. Para Prado ${ }^{29}$, o enfoque sistêmico busca, sempre que houver possibilidade, observar a história familiar e intervir sobre ela, colocando os familiares para interagirem a fim de reviverem juntos alguns pontos importantes de suas próprias histórias que possam lançar luz sobre o presente e ajudem a transformá-lo.

Na prática, parecem existir muitas semelhanças nas abordagens de terapeutas psicodinâmicos e sistêmicos. O conceito de SIS proposto por Cramer \& Palacio-Espasa ${ }^{12}$ - sintoma atuado a dois, no qual se entrelaçam contribuições intrapsíquicas e interpessoais na relação, observável no aqui-agora da sessão - assemelha-se muito ao conceito de função relacional do sintoma da abordagem sistêmica, pois o sintoma é entendido como uma metáfora da disfunção familiar ${ }^{29}$. Assim, para esse autor, "em ambas concepções existe o entendimento de que as interações presentes contém, sempre, as vivências passadas, que se expressam através de modelos ou padrões de funcionamento que cada indivíduo traz consigo desde sua infância e que, em geral, são padrões de interação que se mantêm até o presente entre os pais e os avós" ${ }^{29}$. Stern ${ }^{21}$ corrobora esse ponto de vista, afirmando que tanto a abordagem de Cramer \& Palacio-Espasa quanto a familiar-sistêmica agem direta ou indiretamente para reconectar o mundo representacional da mãe (e por que não do pai?) e do bebê.

Assim, percebe-se que a clínica de bebês pode ser considerada um ponto de encontro entre a abordagem psicodinâmica mãe-bebê de Cramer \& Palacio-Espasa ${ }^{12}$ e a familiar-sistêmica ${ }^{29}$. Em virtude de ambas salientarem a importância de se considerar não somente as questões intrapsíquicas da mãe, mas de todos aqueles envolvidos no cuidado direto com o bebê, o que inclui geralmente o pai, torna-se mais indicado chamar essa abordagem terapêutica de psicoterapia breve pais-bebê ${ }^{29}$. É importante considerar que, nessa concepção, por vezes outros familiares podem também ser solicitados a participar das sessões, como os avós e tios do bebê, o que é sempre previamente combinado com os pais (Piccinini CA, Lopes RC, Prado LC, Gomes AG, Alfaya CA, Schwengber DD, et al. O impacto da psicoterapia breve pais-bebê para a depressão materna e para a interação pais-bebê: estudo longitudinal do nascimento ao segundo ano de vida do bebê [Projeto de pesquisa]. Porto Alegre: Universidade Federal do Rio Grande do Sul; 2004) ${ }^{30}$.

A psicoterapia breve pais-bebê é indicada nos casos de distúrbios psicofuncionais, como de sono e alimentação, em angústias de separação, nos distúrbios de apego e nos distúrbios relacionais pais-bebê $\hat{1}^{12,21,29,30}$. Também podem ser obtidos bons resultados clínicos com mães apresentando depressões desencadeadas pela condição da maternidade ${ }^{12,30}$. Ainda em relação à indicação terapêutica, os pacientes devem ser capazes de articular um problema específico, usualmente derivado de uma experiência interpessoal anterior. Devem ter motivação para mudança em seus padrões interpessoais e capacidade e desejo de se envolver no processo terapêutico (suficiente adaptação do ego) e ter bem delineado ao menos um relacionamento positivo na infância. Nesse sentido, é importante avaliar a qualidade dos relacionamentos interpessoais dos pacientes ${ }^{30}$. Existem algumas contraindicações para essa modalidade de psicoterapia, como os casos de pacientes 
psicóticos, graves transtornos de personalidade, intensa ansiedade de separação, regressão psicótica, tentativas de suicídio, quadros depressivos de vertente melancólica e quadros psicossomáticos ${ }^{12,30}$.

\section{PSI COTERAPI A PAI S-BEBÊ NO CONTEXTO DA DEPRESSÃO MATERNA: ESTUDOS EMPÍ RI COS}

Além de sua contribuição teórico-técnica, o grupo de Cramer \& Palacio-Espasa também se dedicou à realização de pesquisas envolvendo a psicoterapia breve pais-bebê. Estas iniciaram a partir de uma demanda clínica composta por bebês com sintomas psicofuncionais e problemas de comportamento. No decorrer das investigações, os autores, partindo de uma perspectiva teórica relacional, verificaram uma associação desses sintomas com o quadro clínico de depressão materna ${ }^{12}$.

A depressão materna inclui sintomas vegetativos, cognitivos, psicomotores, bem como alterações de humor $^{31-35}$. Caracteristicamente, a depressão materna compreende alterações no apetite e sono, dificuldade de dormir, especialmente após amamentar o bebê, crises de choro, desatenção, problemas de concentração, falta de energia e de interesse em atividades que antes eram consideradas agradáveis ${ }^{33}$. Também podem ocorrer ideias de suicídio e sentimentos excessivos de culpa. Quanto à duração, a depressão pode estender- se por um período de 6 meses a 1 ano após o nascimento do bebê ${ }^{36}$. Os sintomas tendem a ter uma duração razoável de tempo e prejudicam as atividades normais da mulher ${ }^{37}$. Em geral, a duração dos episódios de depressão leva alguns meses e não difere em relação ao tempo de duração de episódios depressivos que não tiveram início no pós-parto ${ }^{37}$. Diversos autores sugerem que, por vezes, a depressão materna pode surgir em algum outro momento do primeiro ano de vida do bebê, e não necessariamente nas primeiras semanas após o seu nascimento, embora ainda fortemente associados à maternidade ${ }^{38-40}$. Quando a depressão da mãe ocorre durante as 4 semanas após o parto, esta é classificada pelo DSM-IV como episódio de depressão maior com início no pós-parto. Para a CID-10, a depressão pós-parto pode surgir durante as 6 primeiras semanas após o parto.

Alguns estudos têm avaliado o impacto da psicoterapia breve pais-bebê sobre a depressão materna, dentre outros aspectos da saúde psicológica da mãe, do bebê e de sua relação. Os estudos descritos por Cramer ${ }^{4-43}$ avaliaram os efeitos da psicoterapia breve para a melhora dos sintomas do bebê, da qualidade da interação mãe-bebê e da autoestima materna. Seus estudos, realizados na Suíça, consistiram no atendimento de diversas famílias com bebês entre 6 e 30 meses de vida. A avaliação familiar ocorreu antes do início do tratamento, 1 semana após o término da terapia, e 6 meses depois. Os resultados, que foram comparados com aqueles obtidos pela orientação interacional ${ }^{25}$, mostraram que ambas as intervenções promoveram a melhora dos sintomas do bebê, assim como a qualidade da interação mãe-bebê. Embora a depressão materna não tenha sido superada completamente, houve uma melhora significativa no estado subjetivo materno, pois, além da autoestima, as mães referiram ter melhorado em outras dimensões, percebendo-se mais calmas, afetuosas, confiantes e bonitas após o tratamento. Além disso, também observaram que seus filhos ficaram mais confiantes e independentes.

Na mesma direção, o estudo de Cooper et al. ${ }^{44}$, realizado na Inglaterra, investigou os efeitos de três diferentes intervenções (psicoterapia breve pais-bebê, terapia cognitivo-comportamental e aconselhamento) para a melhora do estado afetivo da mãe, os quais foram comparados aos efeitos de uma condição controle, que consistia em fornecer às mães apoio nos cuidados primários com o bebê. As três intervenções foram realizadas na residência dos participantes, em um total de 10 sessões, com frequência semanal. Participaram do estudo 193 famílias com mães que apresentavam sintomas de depressão entre a oitava e a 18a semana após o parto, as quais foram designadas a uma das quatro condições. O humor materno foi novamente avaliado logo após a realização das intervenções, bem como aos 9, 18 e 60 meses após o parto. Os autores encontraram que todas as intervenções tiveram um impacto no humor da mãe na primeira avaliação, particularmente os submetidos a psicoterapia breve pais-bebê. Porém, aos 9 e 18 meses não houve diferença significativa no nível de redução dos sintomas entre o grupo controle e os demais. Os autores concluíram que as intervenções para a depressão pós-parto podem melhorar o humor materno por um período breve, mas esse benefício não seria superior à remissão espontânea que se dá ao longo do tempo. Contudo, esses resultados devem ser analisados com cautela, na medida em que os 
autores não exploraram as nuances das modificações observadas na primeira avaliação e não investigaram o porquê das mesmas não se manterem com o tempo.

Em outro estudo dos mesmos pesquisadores ${ }^{45}$, com os mesmos participantes e delineamento descrito acima, os autores avaliaram os efeitos da psicoterapia pais-bebê no relacionamento mãe-bebê e no desenvolvimento posterior da criança. Os resultados revelaram que os relatos sobre problemas de comportamento e de relacionamento com os bebês foram significativamente reduzidos na primeira avaliação. Isso foi atribuído não somente à remissão dos sintomas da depressão materna, mas também ao fato de que os tratamentos proporcionaram às mães a oportunidade de discutirem seus problemas de manejo com os filhos. Já aos 18 e aos 60 meses, os participantes que receberam as intervenções clínicas não diferiram significativamente da condição controle, que consistia em visitas domiciliares que forneciam apoio nos cuidados com o bebê. Os autores concluíram que, embora a intervenção precoce tenha trazido benefícios a curto prazo, intervenções mais prolongadas poderiam ser necessárias.

Esses achados levantam questões acerca da metodologia utilizada no estudo, considerando-se que as mães designadas à chamada condição controle também tiveram acesso a uma intervenção potencialmente benéfica à relação mãe-bebê. É plausível pensar que os resultados seriam diferentes caso os grupos que receberam as intervenções fossem comparados a um grupo que não recebesse qualquer intervenção. Além disso, esse estudo seguiu uma tendência em relação à pesquisa em psicoterapia, que é a pesquisa de resultados, na qual os pesquisadores costumam utilizar-se de instrumentos rigorosos aplicados no início, meio e fim dos tratamentos, sem considerar os fatores de mudança envolvidos no processo terapêutico ${ }^{46}$. Apesar de muitos pesquisadores clínicos preocuparem-se com a investigação do processo psicoterapêutico como variável de grande influência nos efeitos positivos ou negativos dos resultados, outros tantos buscam apenas analisar o "antes" e o "depois", sem verificar a influência do processo na eficácia dos tratamentos. De acordo com as autoras $^{46}$, a preocupação com a avaliação do processo, e não simplesmente dos resultados, deve-se em grande parte às evidências de que abordagens psicoterapêuticas diferentes alcançaram resultados clínicos semelhantes, o que pode ser explicado a partir dos fatores inespecíficos de cada abordagem, como a aliança terapêutica.

No Brasil, pouco se tem publicado sobre estudos sistemáticos envolvendo psicoterapia pais-bebê no contexto da depressão materna. O nosso grupo de pesquisa é um dos que estão trabalhando com essa abordagem. O interesse por essa aplicação da psicoterapia pais-bebê surgiu de estudos realizados anteriormente pelo grupo de pesquisa, os quais verificaram associações entre a presença de depressão materna e dificuldades no funcionamento familiar ${ }^{34,35,47,48}$. Os resultados encontrados nesses estudos apontaram para a necessidade da realização de intervenções frente ao quadro de depressão da mãe, ainda nos primeiros meses após o nascimento do bebê.

Descreve-se, a seguir, as principais concepções teóricas que norteiam a pesquisa sobre psicoterapia breve pais-bebê que vem sendo realizada pelos autores do presente artigo. Os resultados da investigação não serão apresentados em virtude do estudo estar ainda em fase de coleta de dados. Essa intervenção foi baseada em extenso treinamento teórico e prático sobre a psicoterapia breve pais-bebê, realizado pelo supervisor clínico, primeiro autor da presente publicação. No momento, cinco psicoterapeutas-pesquisadoras estão atendendo 22 famílias com mães deprimidas, além de um pequeno grupo de famílias cujos filhos apresentam mal formação. Para fins deste projeto, são realizadas algumas sessões de avaliação inicial, que envolvem mais de dois encontros, a fim de investigar aspectos da história da gestação, das questões relativas à maternidade e à paternidade, sobre o relacionamento conjugal e demais relacionamentos familiares, bem como uma avaliação do desenvolvimento comportamental e socioemocional do bebê. O genograma familiar também é utilizado como recurso técnico na avaliação inicial dos pacientes. Ao final das avaliações, é feita uma entrevista de devolução na qual, caso exista indicação terapêutica para essa abordagem psicoterápica, é combinado o foco da psicoterapia e realizado o contrato das sessões. O processo psicoterápico compreende de oito a 12 sessões semanais, cada uma com duração de aproximadamente 60 minutos. As sessões são gravadas em áudio e vídeo. A participação do bebê é fundamental, pois a observação da interação com ele é um importante elemento de trabalho ${ }^{29}$. O enquadre da sessão terapêutica deve permitir o máximo de interações entre os pais e bebê, a fim de que se possa diagnosticar e intervir na qualidade da relação. O pai também é incentivado a participar da psicoterapia e, conforme a necessidade do caso, outros familiares, como os avós do bebê, são convidados a participar de algumas sessões. Nesse caso, a presença de mais familiares é sempre combinada previamente com a mãe e o pai do bebê. Segue-se a abordagem descrita por 
Cramer \& Palacio-Espasa ${ }^{12}$ e Stern ${ }^{21}$, bem como alguns elementos da abordagem familiar sistêmica ${ }^{29}$.

Há um entendimento de que é importante ajudar a família a construir um contexto favorável para o bom desenvolvimento do bebê, trabalhando-se as relações pai-mãe-bebê. Deste modo, o objetivo principal dessa psicoterapia é melhorar as relações familiares, tanto pais-bebê como entre o casal e sua família de origem. Embora a remissão dos sintomas depressivos maternos não seja o principal alvo da intervenção, espera-se que ocorram melhoras no humor materno ao favorecer relações mãe-pai-bebê mais satisfatórias ${ }^{12}$.

\section{CONSI DERAÇÕES FI NAIS}

O relacionamento inicial pai-mãe-bebê é um alicerce fundamental na dinâmica familiar e no desenvolvimento psicológico dos indivíduos. Neste sentido, acredita-se que a psicoterapia breve pais-bebê, ao intervir nos inúmeros distúrbios que podem ocorrer no relacionamento inicial pais-bebê, pode ser uma abordagem profícua na promoção de vínculos afetivos mais satisfatórios, tendo o potencial de influenciar toda a família e, particularmente o desenvolvimento da criança. A experiência adquirida por este grupo de pesquisa com os atendimentos em psicoterapia pais-bebê no contexto da depressão materna tem mostrado que essa abordagem parece ser efetiva na promoção de um melhor relacionamento mãe-pai-bebê. Em algumas famílias, essa melhora também se estende aos sintomas depressivos da própria mãe.

Desta forma, a psicoterapia breve pais-bebê, ainda que realizada em poucas sessões, pode ser uma alternativa para o alívio dos sintomas no bebê, nos pais e/ou nas relações entre os membros da família. Além disso, por se tratar de uma intervenção realizada nos momentos iniciais da vida do bebê, tem um importante potencial preventivo e de promoção da saúde mental. Sendo assim, estudos empíricos sobre a psicoterapia breve pais-bebê no contexto nacional mostram-se necessários, considerando as particularidades da realidade brasileira, onde pouco se tem investigado o impacto dessa intervenção para a melhora da qualidade de vida das famílias com bebês.

\section{REFERÊNCIAS}

1. Oliveira IT. Psicoterapia psicodinâmica breve: dos precursores aos modelos atuais. Psicol Teor Prat. $1999 ; 1(2): 9-19$.

2. Yoshida E. Evolução das psicoterapias breves psicodinâmicas. In: Yoshida E, Enéas M, eds. Psicoterapias psicodinâmicas breves: propostas atuais. Campinas: Alínea; 2004. p. 13-36.

3. Eizirik CL, Wilhelms FM, Padilha RT, Gauer RH. Psicoterapia breve dinâmica. In: Cordioli AV, ed. Psicoterapias: abordagens atuais. Porto Alegre: Artes Médicas; 1998. p. 145-52.

4. Braier EA. Psicoterapia breve de orientação psicanalítica. São Paulo: Martins Fontes; 1997.

5. Hartke R. Psicoterapia de orientação analítica: resumo histórico de contribuições importantes. In: Eizirik C, Aguiar R, Schestatsky S, eds. Psicoterapia de Orientação Analítica. Porto Alegre: Artes Médicas; 1989. p. 22-48.

6. Greenberg JR, Mitchell SA. Relações objetais na teoria psicanalítica. Porto Alegre: Artes Médicas; 1994.

7. Brazelton TB. O bebê: parceiro na interação. In: Brazelton T, Cramer B, Kreisler L, Schäppi R, Soulé M, eds. A dinâmica do bebê. Porto Alegre: Artes Médicas; 1987. p. 9-23.

8. Brazelton TB. O desenvolvimento do apego. Porto Alegre: Artes Médicas; 1988.

9. Caron N. O ambiente intra-uterino e a relação materno-fetal. In: Caron N, ed. A relação pais-bebê: da observação à clínica. São Paulo: Casa do Psicólogo; 2000. p. 119-34. 
10. Stainton MC. The fetus: a growing member of the family. Family Relations. 1985;34:321-6.

11. Brazelton TB, Cramer BG. As primeiras relações. São Paulo: Martins Fontes; 1992.

12. Cramer BG, Palacio-Espasa F. Técnicas psicoterápicas mãe-bebê. Porto Alegre: Artes Médicas; 1993.

13. Winnicott DW (1956). Da pediatria à psicanálise: obras escolhidas. Rio de Janeiro: Imago; 2000.

14. Bion W (1962). Uma Teoria sobre o Pensar. In: Bion W. Estudos Psicanalíticos Revisados Rio de Janeiro: Imago; 1994. p. 127-37.

15. Mahler M (1975). O nascimento psicológico da criança: simbiose e individuação. Porto Alegre: Artes Médicas; 1993.

16. Spitz R (1965). O Primeiro Ano de Vida. São Paulo: Martins Fontes; 1983.

17. Bowlby J (1969). Apego. São Paulo: Martins Fontes; 1990.

18. Bowlby J. Uma base segura-aplicações clínicas da teoria do apego. Porto Alegre: Artes Médicas; 1989.

19. Fraiberg S, Adelson E, Shapiro V. Fantasmas no quarto do bebê. CEAPIA. 1994; 7:12-34.

20. Lebovici S. O bebê, a mãe e o psicanalista. Porto Alegre: Artes Médicas; 1987.

21. Stern D. A constelação da maternidade: O panorama da psicoterapia pais/bebê. Porto Alegre: Artes Médicas; 1997.

22. Dolto F. Tudo é linguagem. São Paulo: Martins Fontes; 2002.

23. Lieberman AF, Pawl JH. Infant-parent psychoterapy. In: Zeanah C, ed. Handbook of infant mental health. New York: Guilford; 1993. p. 427-42.

24. Pinto EB. Psicoterapia breve mãe/bebê. In: Rockenkohl CF, ed. A clínica com o bebê. São Paulo: Casa do Psicólogo; 2000. p.125-30.

25. McDonough S. Interaction guidance: understanding and treating early infant-caregiver relationship disturbance. In: Zeanah C, ed. Handbook of infant mental health. New York: Guilford; 1993. p. 414-26.

26. Schwengber DD, Alfaya CA, Lopes RC, Piccinini CA. A orientação interacional como alternativa de intervenção precoce pais-bebê no contexto da depressão materna: algumas reflexões iniciais. Psico. 2003; 34:297-316.

27. Andolfi M. Por trás da máscara familiar: um enfoque em terapia familiar. Porto Alegre: Artmed; 1984.

28. Prado LC. Pontes entre concepções psicanalíticas e sistêmicas. In: Prado LC, ed. Famílias e terapeutas. Porto Alegre: Artes Médicas; 1996. p. 17-36.

29. Prado LC. O bebê inaugura a família: a terapia pais-bebê. In: Prado LC, ed. Famílias e terapeutas. Porto Alegre: Artes Médicas; 1996. p. 97-130.

30. Trad P. Psicoterapia breve pais/bebê. Porto Alegre: Artes Médicas; 1997.

31. Alfaya CA, Schermann L. Depressão pós-parto: tendências atuais. Rev Med PUCRS. $2000 ; 10(2): 130-6$.

32. Cruz EB, Simões GL, Faisal-Cury A. Rastreamento da depressão pós-parto em mulheres atendidas pelo Programa de Saúde da Família. Rev Bras Ginecol Obstet. 2005;27:181-8. 
33. Dunnewold AL. Evaluation and treatment of postpartum emotional disorders. Sarasota: Professional Resource Press; 1997.

34. Frizzo GB, Piccinini CA. Interação mãe-bebê em contexto de depressão materna: aspectos teóricos e empíricos. Psicol Estud. 2005; 10:47-55.

35. Schwengber DD, Piccinini CA. Depressão materna e interação mãe-bebê no final do primeiro ano de vida. Psicol Teor Pesq. 2004;20:223-40.

36. Parry BL. Postpartum depression in relation to other reproductive cycle mood changes. In: Miller LJ, ed. Postpartum mood disorders. Washington: American Psychiatric Press; 1997. p. 21-46.

37. O'Hara MW. The nature of postpartum depressive disorders. In: Murray L, Cooper PJ, eds. Postpartum depression and child development. New York: Guilford; 1997. p. 3-34.

38. Brown S, Lumley J, Small R, Astbury J. Missing voices: the experience of motherhood. New York: Oxford University Press; 1994.

39. Klaus MH, Kennell JH, Klaus P. Vínculo: construindo as bases para um apego seguro e para a independência. Porto Alegre: Artes Médicas; 2000.

40. Murray L, Cox J, Chapman G, Jones P. Childbirth: Life event or start of a long-term difficulty? $\mathrm{Br}$ Jour Psych. 1995; 166:595-600.

41. Cramer BG. Are postpartum depressions a mother-infant relationship disorder? Infant Ment Health J. 1993; 14:283-97.

42. Cramer BG. Psychodynamic perspectives on the treatment of postpartum depression. In: Murray L, Cooper PJ, eds. Postpartum depression and child development. New York: Guilford; 1997. p.237-61.

43. Cramer B, Robert-Tissot C, Stern DN, Serpa-Rusconi S, Muralt M, Besson G, et al. Outcome evaluation in brief mother-infant psychotherapy: a preliminary report. Infant Ment Health J. 1990; 11:278-300.

44. Cooper PJ, Murray L, Wilson A, Romaniuk H. Controlled trial of the short and long-term effect of psychological treatment of post-partum depression: impact on maternal mood. Br J our Psych. 2003; 182: 412-9.

45. Murray L, Cooper PJ, Wilson A, Romaniuk H. Controlled trial of the short and long-term effect of psychological treatment of post-partum depression: impact on the mother-child relationship and child outcome. Br Jour Psych. 2003; 182:420-7.

46. Araújo MS, Wiethaeuper D. Considerações em torno das atuais correntes predominantes da pesquisa em psicoterapia. Rev Bras Psicoter. 2003; 5:33-52.

47. Schwengber DD, Piccinini CA. A experiência da maternidade no contexto da depressão materna no final do primeiro ano de vida do bebê. Estud Psicol. 2005;22:143-56.

48. Sotto-Mayor IM. A qualidade do relacionamento conjugal no contexto da depressão materna [dissertação]. Porto Alegre: Universidade Federal do Rio Grande do Sul; 2004.

\section{匇 Correspondência}

Cesar Augusto Piccinini

Instituto de Psicologia, Universidade Federal do Rio Grande do Sul

Ramiro Barcelos, 2600/111

CEP 90035-003, Porto Alegre, RS 
E-mail: piccini@portoweb.com.br

Recebido em 30/01/2008.

Aceito em 14/05/2008.

Não foram declarados conflitos de interesse associados à publicação deste artigo.

O NUDIF integra o Grupo de Pesquisa em Interação Social, Desenvolvimento e Psicopatologia GIDEP da Universidade Federal do Rio Grande do Sul, e faz parte do Diretório de Grupos de Pesquisa do CNPq. Todos os autores do presente artigo integram o NUDIF, com exceção do Dr. Luis Carlos Prado. 